Studia UBB 西igitalia, Volume 65 (LXV), 2020, June, Issue 1, 5-16

Published Online: 2020-12-10

DOI:10.24193/subbdigitalia.2020.1.01

\title{
Epigraphic Squeezes: Digitisation, Publication, and Enhancement
}

\author{
Eloisa Paganoni \\ Ca' Foscari University of Venice
}

\begin{abstract}
Epigraphic squeezes are a key tool for research and teaching. They also have historical and documentary value. They are reliable copies of inscribed text and become the only evidence that remains if inscriptions are lost or destroyed. This paper describes the Venice Squeeze Project for the preservation and enhancement of epigraphic squeezes in the Department of Humanities at Ca' Foscari University of Venice. For the initial phase of the project, the Ca' Foscari University collection of epigraphic squeezes was published in the digital ektypotheke E-stampages. The current phase involves developing a web application to digitise epigraphic squeezes according to the metadata architecture of E-stampages. The first part of this paper describes the background of the Venice Squeeze Project and methodological issues, which fostered the partnership with E-stampages. The second part describes the relational database that was set up to digitise the Ca' Foscari collection. The third part introduces the project initiatives to promote a network of Italian institutions interested in digitizing their collections of epigraphic squeezes.
\end{abstract}

Keywords: Greek epigraphy, squeezes, database architecture

\section{Introduction}

An epigraphic squeeze is a facsimile of an inscription. Nowadays, squeezes are generally made of acid-free chemistry filter paper but until some years ago, they were also made of plaster or latex (McLean 67-73). The squeeze is one of the most important tools for epigraphers. In providing an exact reproduction, it allows epigraphers to check the legibility and disposition of the text as well as the shape of the letters on the stone.

The squeeze is a testimonium to the preservation of an inscription at the time it was made. Squeezes produced in the late nineteenth to early twentieth century show a better state of preservation than those of the same inscriptions made today. Many 
stones are not stored in museums but left at the place of discovery. They remain exposed to weather that washes away the surface, making inscribed signs harder to decipher. Stones are often lost both museums and at archaeological sites, especially if they are small fragments. They can also be destroyed during events such as wars or natural disasters.

These eventualities suggest that the squeeze could easily become the best (or the only) testimonium of an inscription. Squeezes are more than simply by-products of the activities of epigraphers, as they have long been regarded: they are heritage with an intrinsic documentary and cultural value. Several institutions promote projects to safeguard and enhance this form of documentation, and their projects often result in digital collections of epigraphic squeezes. ${ }^{1}$ This paper presents the initiatives promoted by Prof. Claudia Antonetti (Department of Humanities, Ca' Foscari University of Venice) within the framework of the Venice Squeeze Project (VSP).

\section{The Ca' Foscari collection and the Venice Squeeze Project}

The Department of Humanities at Ca' Foscari University of Venice hosts a collection of 605 epigraphic paper squeezes. The collection was built up from the late 1970 s to 2000 s by Claudia Antonetti, who donated it to the Department of Humanities in 2019. ${ }^{2}$ It thus reflects the development of Claudia Antonetti's research interests since the beginning of her career. She produced squeezes for her early study on Sicily. Over five hundred squeezes were made from inscriptions on the museums of Agrinion, Thermos and Thyrreion, which now lie in the Aitoloakarnania region. They are connected to Antonetti's studies on the epigraphic culture of Central Greece, one of her primary research areas over time. Then, a small but significant group of squeezes were made from inscriptions preserved at the museums of Venice and Veneto region. A few squeezes were donated by scholars who collaborated with Claudia Antonetti.

This is the richest and most coherent collection of epigraphic squeezes in Italy. It has contributed to making Ca' Foscari a hub for teaching on Greek Epigraphy. Every year, undergraduate and graduate students practice reading epigraphic squeezes. Thanks to squeezes of inscriptions dating from the Archaic to Roman Imperial eras, students learn to recognise alphabets and lettering from different ages and regions. They acquire knowledge and skills that could otherwise only be gained through a visual autopsy of the original documents. Although Greek Epigraphy has been penalised in higher education programmes in recent years, both in Italy and elsewhere, the enthusiasm of participating students speaks to the lively interest in inscriptions (Paganoni et al.).

\footnotetext{
${ }^{1}$ See the digital collections of Princeton University (https://www.ias.edu/krateros), the CSAD of the University of Oxford (https://www.csad.ox.ac.uk/squeeze-collection-0), the British Institute of Ankara (https://www.biaatr.org/squeeze), and the Aleshire Center for the Studies of Greek Epigraphy of the University of California (http://aleshire.berkeley.edu/holdings/images).

2 https://www.unive.it/pag/16969/.
} 


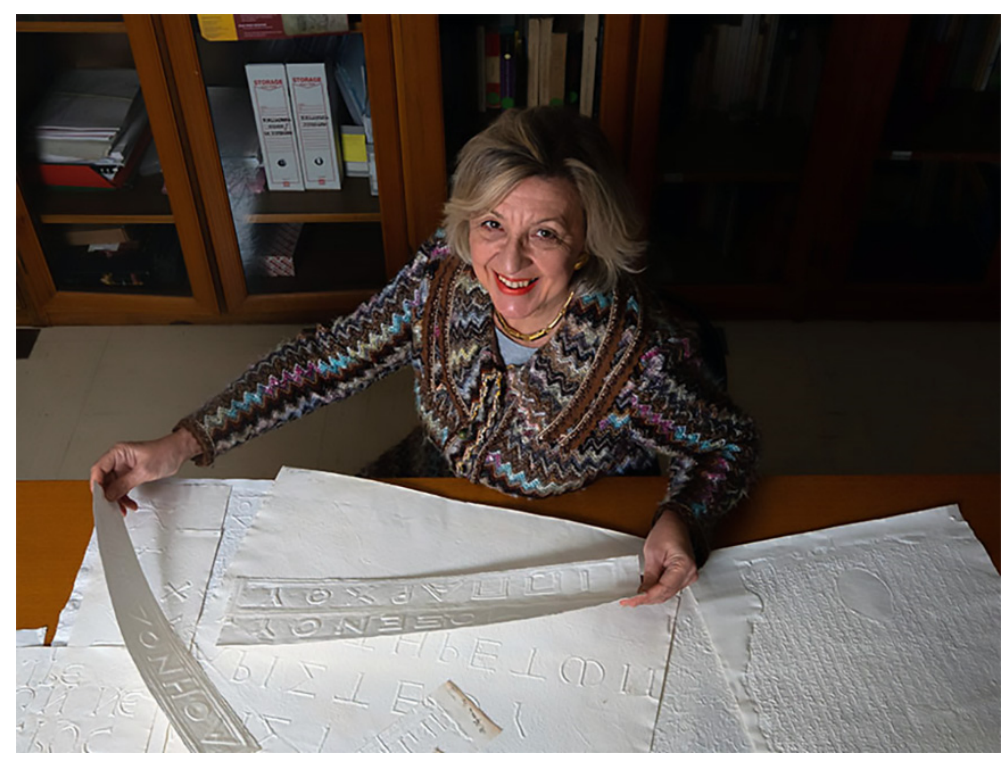

Fig. 1. Claudia Antonetti and some of her squeezes. Photo by Paolo Della Corte. Courtesy of Claudia Antonetti

Certain that squeezes were an invaluable resource to both scholars and students, Antonetti embarked on a series of initiatives under the name of the Venice Squeeze Project (VSP) to make her collection widely available (Antonetti et al. "Digital epigraphy" 491-495; Antonetti et al. "Collezioni"). ${ }^{3}$ In 2012, she promoted a reorganisation of the collection. It was arranged according to geography, and squeezes were given an inventory number. She then launched the first digitisation of the collection, creating a FileMaker archive. The archive collected basic information on the squeezes and the inscriptions they were made from along with photos of the reverse and the obverse of the squeezes as well as the inscriptions themselves ${ }^{4}$. This was used in the research and teaching activities of the members of the Laboratory of Greek Epigraphy.

In 2017, Ca' Foscari University funded a second phase of the VSP to publish the university collection online and contribute to the enhancement of other Italian collections of squeezes. Online publication posed new challenges as it required a suitable method to reproduce and describe the squeezes in a digital environment. Claudia Antonetti contacted her colleague Prof. Michèle Brunet (University of Lyon 2), who was developing the E-stampages project with aims analogous to those of the VSP. In view of the shared aims and methods of these projects, they established an official partnership that led to publication of the Ca' Foscari squeezes in the EStampages digital collection.

\footnotetext{
${ }^{3}$ http://mizar.unive.it/venicesqueeze/public/frontend.

4 Michela Socal designed and implemented the FileMaker archive.
} 


\section{E-stampages: a Digital Ektypotheke}

Under the leadership of Michèle Brunet, the E-stampages project (Levivier et al.; Antonetti et al. "Collezioni" 42-48), ${ }^{5}$ aims to digitise a number of epigraphic squeezes of the Laboratoire HiSoMA (Histoire et Sources des Mondes Antiques, Maison de l'Orient et de la Méditerranée, Lyon), and the EfA (École française d'Athènes) ${ }^{7}$. In addition to the Laboratoire HisoMA and the EfA, the original consortium of E-stampages included two other partners: the Pôle Système d'information et réseaux de la Maison de l'Orient et de la Méditerranée Jean Pouilloux (MOM), ${ }^{8}$ which provided the planetary scanner for the creation of digital images and supported the setup of the CMS (Content Management System) for online publication; and the Digital Epigraphy and Archaeology Project, which provided the 3D software. ${ }^{9}$ Thanks to the proposal of collaboration submitted by Michèle Brunet and Claudia Antonetti to the EfA, the VSP joined this consortium in 2017. The VSP then adopted the E-stampages' metadata architecture and published the Ca' Foscari collection on the French website. The collaboration between the VSP and E-stampages took their shared aim into account and recognised that E-stampages proposed the most sophisticated and innovative digitisation protocol for the collection of squeezes.

E-stampages intends to create a digital ektypotheke. This term is composed of the word ektypon, which means 'squeeze' in Modern Greek and derives from the Ancient Greek word for 'object in relief', and the suffix -theke ('collection'). The word ektypotheke clarifies the aim and methods of E-stampages by stressing that the squeeze (and not the inscription or the text) is the focus of the digital resource. The metadata architecture derives from this as the squeeze is at the centre of the digital resource, while information about the stone, text, and images is arranged around it. Ektypon reminds us that a squeeze is an object in relief. This is the key feature that allows epigraphers to read squeezes. Thus, it had to be preserved in the digital environment via a 3D model (Antonetti et al. "Collezioni" 43).

E-stampages partners (HiSoMA, EfA, and VSP) follow the same protocol for dataset and image preparation. Michèle Brunet and Adeline Levivier developed the metadata architecture in 2016, which was then further refined during a meeting of the partners at the EfA in 2018. ${ }^{10}$ This metadata architecture is composed of five interrelated entities. The first entity, the squeeze, is linked to the entities of the $2 \mathrm{D}$ images, the 3D model, and the text. The text is connected to the final entity, the artefact (that is, the object). The text description includes a reference to the editio princeps or

\footnotetext{
${ }^{5}$ https://www.E-stampages.eu/s/E-stampages/page/accueil. I thank Michèle Brunet for allowing me to introduce E-stampages.

6 https://www.hisoma.mom.frl.

${ }^{7}$ https://www.efa.gr/index.php/fr/ressources-documentaires/les-archives/archives-estampages/leprogramme-E-stampages.

8 https://www.mom.fr/les-services-de-la-federation/pole-systeme-d-information-etreseaux/presentation.

9 See below in this paragraph.

${ }^{10}$ For HiSoMA and MOM: Michèle Brunet, Adeline Levivier, Richard Bouchon, Bruno Morandière and Hélène Vuidel; for the EFA: Marie Stahl, Louis Mulot, Anaïs Michel, Nicolas Genis and Julien

Fournier; for the VSP: Claudia Antonetti and Eloisa Paganoni.
} 
the reference edition; if needed, an entry from the Supplementum Epigraphicum Graecum is added to highlight a contribution that significantly adds to the reading of the reference edition. Bibliographical references are managed via Zotero. ${ }^{11}$

Research groups within the HiSoMA, EfA, and VSP had earlier produced datasets that were already available, but these needed to be expanded and synchronised. Teams entered missing information and carried out a redocumentarisation of the datasets by adding metadata needed to describe digital items and make them function. Metadata was organised according to a hierarchy that is searchable, interoperable, and reusable according to the instructions of the $3 \mathrm{~W}$ Consortium on the development of the Semantic Web.

Using either a planetary scanner or a camera, the teams produced a series of digital images for each squeeze ${ }^{12}$ :

2 files TIFF (400 dpi) of the obverse and reverse for long term storage;

2 files PNG (400 dpi) of the obverse and reverse for online publication;

2 files PNG (200 dpi) of the reverse, rotating the light exposure by $90^{\circ}$, for the 3D model.

The 3D model was produced using DEA software. This software was developed by Eleni Bozia and Angelos Barmpoutis at the University of Florida as part of the Digital Epigraphy and Archaeology Project (Bozia et al.). ${ }^{13}$ It produces a 3D model that can be embedded and displayed in web pages. Users may move, rotate, zoom in, zoom out, or change the shading and visualisation mode to see details that are otherwise invisible.

Datasets from the three partners (HiSoMA, EfA and VSP) are stored and distributed on the internet by The Huma-bum Box ${ }^{14}$ and the service Nakala ${ }^{15}$ of the Très Grande Infrastructure de Recherche nationale française (TGIR) Huma-Num. ${ }^{16}$ Collections of epigraphic squeezes are published on the E-stampages website, which is managed through the CMS (Content Management System) Omeka S. ${ }^{17}$ This CMS requires no advanced IT proficiency to arrange datasets for online publication. Furthermore, it allows for data exploration in several-and in some cases unprecedented-ways.

A beta version of the E-stampages website was presented at the Sixth 'Seminario Avanzato di Epigrafia Greca' held in Venice in January 2019. The first version of the E-stampages website, which hosted a sample of the HiSoMA and EfA squeezes of Thasos and Ca' Foscari squeezes of the Museum of Agrinion, was released shortly after. The online collection has steadily expanded since then to include other squeezes from Thasos and the remaining squeezes of the Ca' Foscari collection, which are now completely available online.

\footnotetext{
11 https://www.zotero.org.

12 Scanner models: Digibook Zeutschel (in Lyon), Copibook ${ }^{\mathrm{TM}}$ Cobalt (in Venice).

13 https://www. digitalepigraphy.org.

14 https://humanum.hypotheses.org/2711.

15 https://www.huma-num.fr/services-et-outils/exposer.

16 https://www.huma-num.fr/.

17 https://omeka.org/s.
} 
The E-stampages website is organised into six sections. The first two sections introduce the project and describe the digitisation protocol. 'Les collections' describes the collections published on the website; from this section, users can explore each collection by provenance and number of squeezes. 'Les estampages par provenance' presents squeezes by a geographical criterion. The following section, 'Parcourir toutes les collections', allows exploration of collections by object and text types. The last section currently available, 'Bibliographie \& liens web', lists the project contributions and the collections published on the Estampages website. Another section currently under development, 'Portraits d'épigraphistes', will host temporary exhibitions on epigraphy with a focus on influential scholars that have shaped the discipline.

\section{The Venice Squeeze Project database}

Partnership between the VSP and E-stampages was facilitated by a common aim (the online publication of a squeeze collection), but it also responded to relevant methodological questions. E-stampages offers the most articulate means for the online publication of epigraphic squeezes. Its metadata architecture focuses on the squeeze itself and provides a full description of the text and inscription. A holistic concept of the squeeze thus underlies metadata architecture as it considers all features describing or attached to the squeeze. This descriptive care helps transform squeezes from byproducts of the activities of epigraphers into pieces of heritage with historical and documentary value. The digital images and 3D models provide users with an accurate digital reproduction of the squeezes.

Furthermore, the partnership aims to overcome fragmentation featuring digital resources. It is hard to keep pace with the ever-increasing number of resources that have become available in recent years. Some resources (the smallest and most specific ones, above all) are inevitably overlooked or underexploited. Cooperation between similar initiatives may limit fragmentation and publishing small collections in one repository boosts their potential dissemination.

The VSP team created a new MySQL relational database to prepare metadata for publication in the digital ektypotheke of E-stampages. Luigi Tessarolo, the IT technician for the project, developed the software to manage the database-not via a CMS, but directly in PHP within the Zend Framework. ${ }^{18}$ Realised between the end of 2017 and spring of 2018, the VSP database was planned as a tool to prepare the dataset for E-stampages and to set up a searchable digital archive that could substitute for the FileMaker archive.

Designing a database offers several advantages. For one, it ensures maximum flexibility in modelling metadata architecture and export modes. A database allows data to be easily controlled, checked, and corrected. Input methods such as dropdown menus give access to controlled vocabularies so ambiguous terms and typos can be avoided. Upon finding a mistake, the user intervenes only once to correct wherever it appears. For another, the software managing the database enters and

${ }^{18}$ https://framework.zend.com. 
manages several data automatically. The software also supports re-documentarisation by generating record identifiers (ID) and connections among records (Antonetti et al. "Collezioni", 57-59). This serves to guarantee the functioning of the database and the structure of the dataset as the software automatically manages images, 3D models, and metadata. Finally, the database permits re-use of the dataset from the FileMaker archive, which has become a starting point for a new round of digitisation.

Accessible to project members only, the VSP database is hosted on the Mizar.unive.it server run by the ASIT (Area Servizi e Telecomunicazioni) at Ca' Foscari University. ${ }^{19}$ The database reproduces the E-stampages metadata architecture composed of the five entities: squeeze, text, artefact (that is, the stone), the 2D images, and the 3D model. The user inputs only information that the software cannot enter automatically. Accordingly, (s)he intervenes in some fields for the squeeze, text, and artefact entities. The implementation process moves from the artefact to the squeeze to ensure the correct relationship between the two. Relations may indeed be complex: an artefact may bear (and thus, be related to) more than one text; and text may be reproduced (and thus, related to) for more than one squeeze. The other entities (the 2D images and 3D models) are implemented automatically, as we will see.

As with the Ca' Foscari collection itself, the database is in Italian and arranged by region. Populated with the dataset from the FileMaker archive, the database generated all instances of the artefact, text, and squeeze entities necessary to describe the items of the Ca' Foscari collection. Then, any instances missing data were updated and completed. When accessing the database, the home screen shows a list of squeezes with some additional information (place of discovery, date of inscription, and key editions). Selecting an entry on this list, the user accesses three subsequent boards that allow him/her to enter data on the stone, the text, and the squeeze: a screen about the artefact leads to one about the text, and then one about the squeeze. This latter screen is divided into two parts that show fields for implementation on the right, and photos of the reverse and obverse of the squeeze on the left. The black-and-white, low resolution images were imported from the FileMaker archive and preserved to support the new digitisation. When available, the 3D model is displayed below the photos.

Three input methods are used to enter data: drop-down menus, checkboxes, and free-form fields. Most data entries are accessed via drop-down menus, and options are selected according to E-stampages controlled vocabularies. This method is also used to enter inscription origin and place of discovery. There is no point in establishing a default list of place names as it forms while the cataloguing of squeezes progresses. However, strict controls are needed for the names of places. The spelling of a place name may vary according to time and language. For example, the name Delphi is spelled Delphoi in Ancient and Modern Greek, Delfi in Italian, and Delphes in French. It is easy to create duplicates and in order to avoid this, the VSP database manages the names of places. To search for a place, the user first adds the name to the menu (viz. for place of discovery) and then selects the entry from the menu. Thereafter, the user can select the same place from the list of names already recorded as needed.

19 https://www.unive.it/data/strutture/111575. 


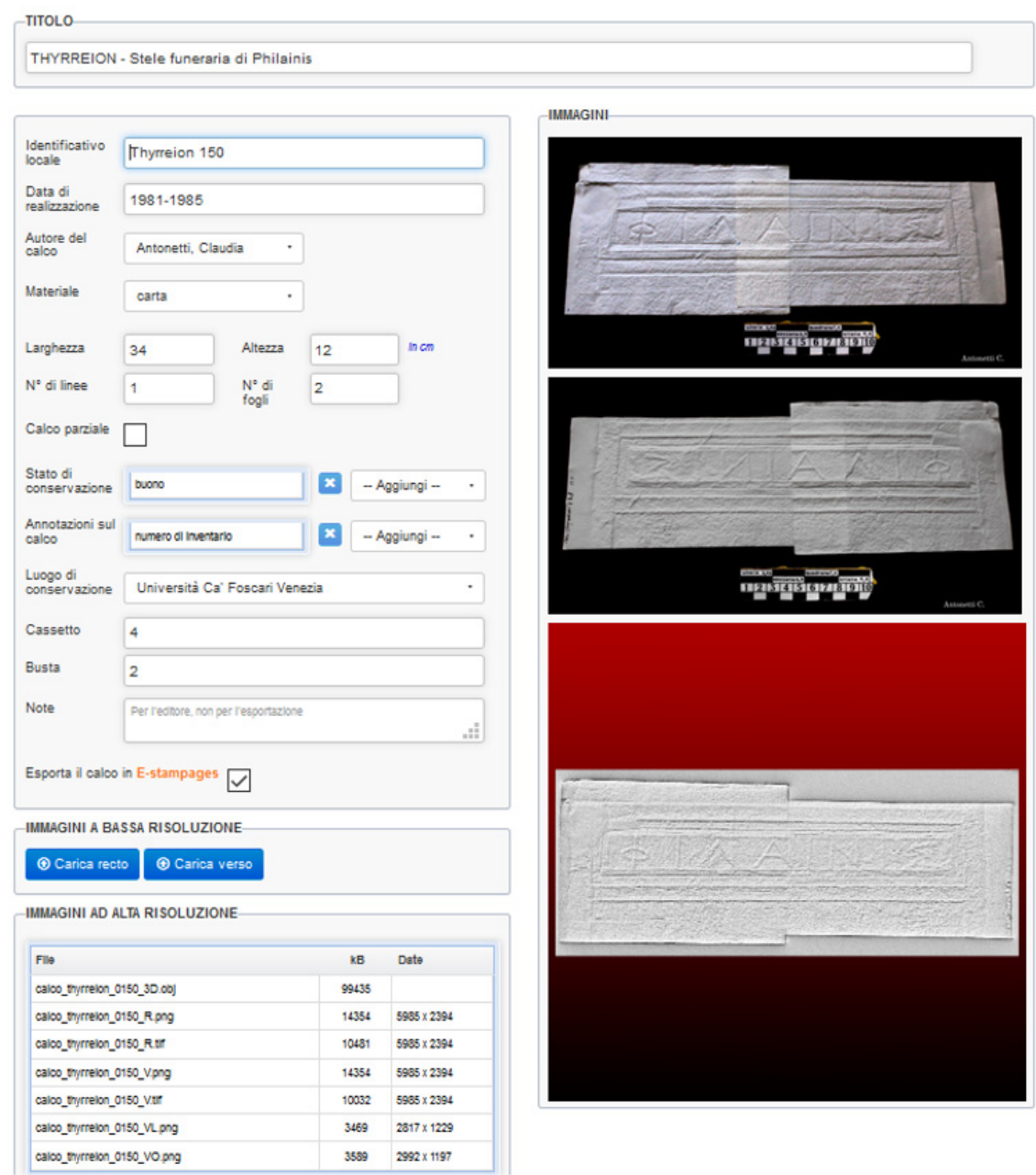

[Fig. 2. VSP database. Sample of the screen of the squeeze. Thyrreion 150 - Funerary inscription of Philainis (CEGO 2, 269). Courtesy of Claudia Antonetti].

Checkboxes allow for selection between two options or the entry of commands managed through Boolean-typed variables. For example, the user ticks a checkbox to indicate whether a stone is complete, fragmented, or lost; or to indicate whether the script is regular or irregular. Databases can easily manage certain information that is lost or unknown. When a piece of information (such as the addressee of a text) is unknown in the VSP database, the user leaves the field empty and the software autofills it with the word ignoto (unknown). A piece of information can be uncertain as well, and encoding uncertainty is a great challenge to digital humanists. When a piece of information is uncertain in the VSP database, the user ticks the checkbox incerto (uncertain) beside a field. If a decree was probably passed in Athens, for instance, the user enters the word 'city' in the field 'issuing authority' and checks the box marked 'uncertain' next to it. When exporting data, uncertainty can be translated in several ways. According to E-stampages guidelines, uncertain data appear in square brackets. As checkboxes also serve to enter commands, they can be used to indicate whether a squeeze should be exported to E-stampages. In some cases, an inscription has more than one squeeze as there may be duplicates or reproductions of part of a 
stone. These are included in the VSP digital archive as part of the Ca' Foscari collection, but not published on the E-stampages website. After entering data, the user ticks the checkbox 'export to E-stampages' if the squeeze needs to appear in the online collection.

Drop-down menus and checkboxes are used to enter most information as they allow for data control. The VSP database requires a few free-form fields as well: the title and the note fields. According to the requirements, each instance of the artefact, text, and squeeze entities must include a title that contains information needed to identify the entity record. The artefact title, for instance, indicates the place of origin, object type, text type, and key edition (viz. the item 'Thermos 16' in the Ca' Foscari collection has the artefact title 'THERMOS - Stele con dedica di una associazione religiosa a Dioniso : IG IX 1(2) 1, 117'). ${ }^{20}$ In the VSP database, the field 'notes' allows for additional remarks about specific aspects. While irrelevant to digitisation, these notes may record details significant to the study of the document.

The FileMaker archive includes oblique light photos of the squeezes. When the second phase of the VSP began, a new image archive needed to be produced according to the technical specifications of E-stampages. Most of the images for longterm storage, online publication, and 3D models were produced using the BAUM (Biblioteca di Area Umanistica) planetary scanner at Ca' Foscari University ${ }^{21}$. In October 2019, AMS Archive Services LTD (Athens) digitised approximately sixty squeezes that could not be captured by the scanner. ${ }^{22}$ Due to the large number and dimensions of the photos, the image archive is not stored on the server. Instead, it is stored on a hard disk along with a back-up copy on a cloud service (Google Drive). Images are organised in folders containing both the images and 3D model of each squeeze. Java software then reads and exports the image data to a CSV file. Finally, the file is imported into the VSP database via FTP (File Transfer Protocol). ${ }^{23}$ This process creates the entities of the $2 \mathrm{D}$ images and $3 \mathrm{D}$ reconstructions.

Once the dataset is complete, the database is ready to prepare data for the $E$ stampages digital collection and to support the research and teaching activities of epigraphers at Ca' Foscari University. Exporting data from the database is easy and quick: the VSP database has an export function that can be applied to the whole dataset or just part of it (such as data on squeezes of inscriptions from Thermos). Data are exported in five CSV files as each file contains data on one entity. For images, the Java software copies files shared with E-stampages. An advanced search tool has been set up to browse the database. Users can set a range of one to ten search criteria (including inscription place of origin, discovery, and preservation; text type; object type; and edition) and explore data via a search bar.

\footnotetext{
20 https://www.e-stampages.eu/s/e-stampages/item/5595.

21 https://www.unive.it/baum.

${ }^{22}$ AMS Archive Services LTD: http://www.scanning.gr/el/. The digitisation of these squeezes was funded by the École française d'Athènes.

${ }^{23}$ FileZilla Client was used: https://filezilla-project.org.
} 


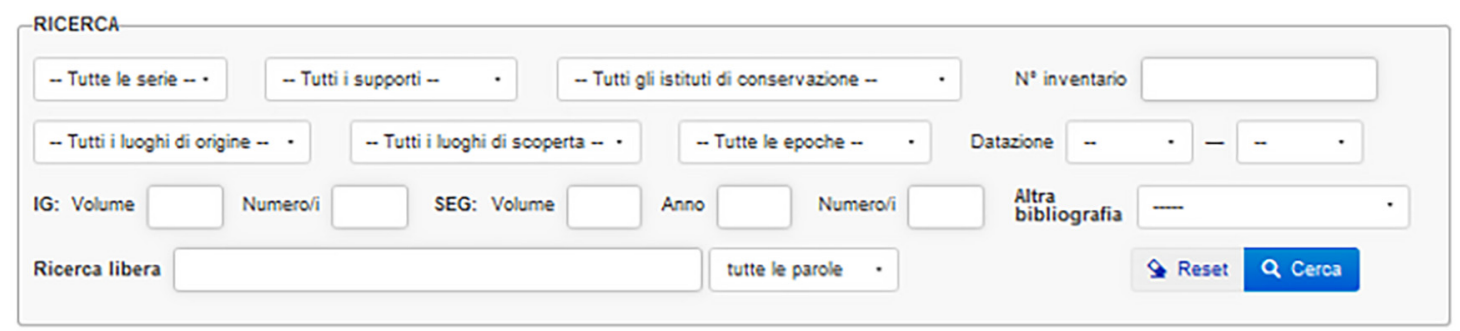

Fig. 3. VSP database. The search tool. Courtesy of Claudia Antonetti.

\section{Future developments}

The VSP aims to promote recognition of epigraphic squeezes as historical and documentary evidence. In this sense, it supports the promotion of other collections of epigraphic squeezes. When the project began, a few Italian collections were known to exist. ${ }^{24}$ No up-to-date information about the extent, preservation, and organisation of these collections was available. Due to a long tradition of study in Greek and Latin Epigraphy, they were supposed to make up only a small portion of the collections preserved in Italian institutions. For this reason, the VSP team surveyed scholars, universities and archaeological museums to bring 'forgotten' collections to light.

The results still preliminary, so remarks on the scope, state of cataloguing, and preservation of these collections are necessarily limited. So far, the survey has reported nine collections. The most significant include from 160 to around 250 squeezes, while the small ones contain just a few specimens. Four collections are entirely uncatalogued, and one is partly catalogued. For three collections, the number of items is unknown. These results are not surprising as squeezes often lie neglected in the closet of a department or museum for years. They are sometimes even forgotten, as illustrated by the Palazzo Altemps collection in Rome that was quite large (174 squeezes) and found by chance behind a closet a few years ago. ${ }^{25}$ The surveyed collections are mainly comprised of paper squeezes, but two contain plaster and latex squeezes: La Sapienza has 120 plaster squeezes, while the Scuola Normale Superiore collection in Pisa consists of 49 latex squeezes. ${ }^{26}$

Scholars recognise the importance of the epigraphic squeezes, but they lament the barriers facing initiatives to safeguard and enhance squeezes. It is difficult to find support from institutions as a cost-benefit analysis discourages the digitisation of small collections. Creating and managing an online collection is expensive. Publishing each collection on its own website increases costs and reduces visibility. Although a digital archive can be useful for collection management, digitisation without online publication cannot be taken into account.

\footnotetext{
${ }^{24}$ The collections of La Sapienza University (see Bevilacqua) and the Scuola Normale Superiore.

${ }^{25}$ Claudia Antonetti and I thank Silvia Orlandi for this information.

${ }^{26}$ Claudia Antonetti and I thank Francesco Camia and Francesco Guizzi for information about the collection of La Sapienza University, and Carmine Ampolo and Anna Magnetto for that on the collection of the Scuola Normale Superiore.
} 
The existence of a network, tools, and metadata standards would foster new initiatives to safeguard and enhance the archives of epigraphic squeezes. Thanks to support from the Venice Centre for Digital and Public Humanities, ${ }^{27}$ the VSP is developing a web application that will be made available to those who wish to create their own digital collection. A beta version of the web application in Italian and English is nearly ready. It will be tested by scholars from the Archeological Mission in Cyrenaica, and the Universities of Bologna, Macerata and Tor Vergata. ${ }^{28}$

The new application consists of web-based software running a database that complies with E-stampages standards. It is modelled on the VSP database but overcomes its technical shortcomings. The most relevant novelty concerns image management. As detailed earlier, the VSP image archive is not stored on a server but on a hard disk; data transfer from the archive to the database requires local software and an FTP connection. In the future, images will be archived on cloud storage linked to the new application. The application will read and import image data into the database automatically. As with the VSP database, users will enter information. Once the data is entered, the database will serve as a digital archive that will contribute to the preservation and everyday use of the collection. Institutions that want to publish digital collections online will be able to export both the dataset and the images. Collections may be published on the E-stampages website as the data and images comply with the standards of the French programme. Alternatively, institutions may choose to publish collections on their own websites. This application is conceived as a flexible tool that complies with high-quality digitisation standards. It meets the needs of those who wish to digitise a collection for preservation and management purposes, and of those who wish to publish them.

The survey also brought the existence of plaster and latex squeezes to light. Their digitisation requires a protocol that takes their specific features into account. Descriptive metadata may remain unchanged-perhaps only an additional field for the thickness of the squeeze is needed. But the DEA software works only for paper squeezes, so a 3D model cannot be produced. The VSP team is going to establish a collaboration with IUAV University of Venice ${ }^{29}$ to explore other 3D modelling techniques for squeezes made of paper and/or other materials.

\section{Conclusion}

Initiatives such as the VSP and E-stampages attest to fresh interest in epigraphic squeezes. The VSP intends to support the rise of an Italian network for the preservation and enhancement of epigraphic squeeze collections by offering institutions a web application to launch their digitisation programmes. Positive response to the survey of Italian collections indicates lively interest; hopefully, other

\footnotetext{
${ }^{27}$ https://www.unive.it/pag/39287.

28 The beta version was scheduled for presentation at a two-day workshop in Venice held in May 2020 , which was postponed indefinitely due to the 2020 health emergency. With participation from Michèle Brunet and the VSP team, the workshop would have presented the outcomes and future developments of the VSP and E-Stampages.

${ }^{29}$ http://www.iuav.it/homepage.
} 
collections will be digitised in coming years. As with the VSP and E-stampages, these programmes will aim both preserve squeezes and make them available for scholars and students. They will contribute to safeguarding archives of epigraphic squeezes, recognising their documentary and historical value.

Ongoing and future programmes acknowledge epigraphic squeezes as heritage that should be protected, as through digitisation. This operation generates a digital reproduction of an object (a piece of heritage). In meeting high-quality standards, the digital reproduction itself becomes heritage. Accordingly, we now face a two-fold challenge: safeguarding squeezes as both tangible and digital heritage. Safeguarding archives of epigraphic squeezes is likewise essential for guaranteeing the long-term survival of current and future digital collections. In this sense, the creation of a network of institutions could be fundamental.

\section{Bibliography}

Antonetti, Claudia, Michèle Brunet, and Eloisa Paganoni. "Collezioni di calchi epigrafici: una nuova risorsa digitale". Axon, vol. 3, no. 2, 2019, pp. 41-66, https://edizionicafoscari.unive.it/media/pdf/article/axon/2019/2/art-10.14277-

Axon-2532-6848-2019-02-004.pdf

Antonetti, Claudia, Stefania De Vido. "Digital Epigraphy at the Greek Epigraphic Laboratory, Ca' Foscari University of Venice". Historika, vol. 7, pp. 491-502, https://www.ojs.unito.it/index.php/historika/article/view/2608/2442

Bevilacqua, Gabriella. "Da Federico Halbherr a Luigi Moretti, il percorso dell'epigrafia attraverso i calchi epigrafici della Facoltà di Lettere e Filosofia" dell'Università di Roma 'La Sapienza'. Mediterraneo Antico, vol. 16, 2013, pp. 563-582.

Bozia, Eleni, Angelos Barmpoutis, and Robert S. Wagman. "Open-Access Epigraphy. Electronic Dissemination of 3D-digitized Archaeological Material". Information Technologies for Epigraphy and Cultural Heritage. Proceedings of the First EAGLE International Conference, edited by Silvia Orlandi, Raffaella Santucci, Vittore Casarosa, Pietro Maria Liuzzo, Roma: Sapienza Editrice, 2014, pp. 421435, https://www.eagle-network.eu/wp-content/uploads/2015/01/Paris-ConferenceProceedings.pdf

Levivier, Adeline, Elina Leblanc, and Michèle Brunet. "E-STAMPAGES: archivage et publication en ligne d'une ectypothèque d'inscriptions grecques". Les nouvelles de l'archéologie, vol. 145, 2016, pp. 24-27, https://journals.openedition.org/nda/3801

McLean, Bradley H. An Introduction to Greek Epigraphy of the Hellenistic and Roman Periods from Alexander the Great down to the Reign of Constantine (323 B.C.A.D. 337). Ann Arbor: The University of Michigan Press, 2002.

Paganoni, Eloisa, Stefania De Vido, and Claudia Antonetti. "II Laboratorio di Epigrafia Greca dell'Università Ca' Foscari. Una fucina didattica per l'epigrafia greca". 8th Annual Conference AIUCD 2019. Udine, 23 - 25 January 2019. Teaching and Research in Digital Humanities'Era. Book of Abstracts. Udine, 2019, pp. 193-195, http://aiucd2019.uniud.it/book-of-abstracts. 